\title{
Radiofrequency treatment for electrical storm: Evolution and monitoring
}

\author{
Tratamiento con radiofrecuencia de la tormenta eléctrica: evolución y seguimiento
}

\author{
Pablo M. Ruiz-Hernández ${ }^{1,3}$, Felipe Atienza1,2,3*, Leonel Díaz-González,3, Gerard Loughlin ${ }^{1,3}$, \\ Esteban G. Torrecilla ${ }^{1,2,3}$, Pablo Ávila1,3, Tomás Datino ${ }^{1,3}$, Ángel Arenal ${ }^{1,3}$,and \\ Francisco Fernández-Avilés ${ }^{1,2,3}$ \\ ${ }^{1}$ Department of Cardiology, Hospital General Universitario Gregorio Marañón, Instituto de Investigación Sanitaria Gregorio Marañón; ${ }^{2}$ Faculty of \\ Medicine, Universidad Complutense de Madrid, ${ }^{3}$ Centro de Investigación Biomédica en Red de Enfermedades Cardiovasculares (CIBERCV), \\ Instituto de Salud Carlos III. Madrid Spain
}

\begin{abstract}
Introduction and objective: Electrical storm (ES) is characterized by repeated episodes of ventricular tachycardia or ventricular fibrillation, with poor short- and long-term prognosis. Our objective was to evaluate the prevalence, results of interventional treatment and survival of patients undergoing interventional treatment for ES in our center. Methods: This study was retrospective, unicentric, and observational study. ES ablation procedures were revised and data regarding baseline characteristics of the patients, type of procedure, total mortality, recurrence of arrhythmia, cardiovascular mortality, and the need for transplantation were evaluated. Results: From January 2009 to December 2016, 67 procedures (38\% complex procedures: $19 \%$ epicardial ablation, $7.5 \%$ surgical epicardial crioablation, 3\% simpatectomy, 3\% coronary alcohol injection, $6 \%$ extracorporeal membrane oxygenation support) were performed in 41 patients (61\% Ischemic etiology) due to ES. Intraprocedural mortality was 1.5\%. The median follow-up was 23.5 months (interquartile range 14.2-52.7). After the first admission for ES (one or several procedures), 1-year mortality was $9.8 \%$. The cumulative incidence of cardiac transplantation was $2.4 \%$. The risk of arrhythmic recurrences or death was significantly higher in patients with inducible clinical arrhythmias after ablation (HR: 9.03, $p=0.017$ ). Conclusion: The treatment of patients with ES, performed in a reference center, allows obtaining good rates of recurrence and survival, with very low rates of cardiac transplantation for ES. In the presence of an early recurrence, it is advisable to perform a new procedure during admission.
\end{abstract}

Key words: Electrical storm. Catheter ablation. Ventricular tachycardia. Ventricular fibrillation.

\section{Resumen}

Introducción y objetivos: La tormenta eléctrica (TE) se caracteriza por episodios repetidos de taquicardia ventricular 0 fibrilación ventricular relacionados con mal pronóstico a corto y largo plazos. El objetivo fue evaluar la prevalencia, resultados y supervivencia de los pacientes sometidos a tratamiento intervencionista por TE en un centro de referencia. Métodos: Estudio unicéntrico, observacional y retrospectivo. Se revisaron los procedimientos de ablación por TE y se evaluaron las características

\section{Correspondence:}

*Felipe Atienza

E-mail: fatienzaf@secardiologia.es

DOI: 10.24875/ACME.M20000146
Available online: 02-03-2021

Arch Cardiol Mex (Eng). 2020;90(4):345-353

www.archivoscardiologia.com license (http://creativecommons.org/licenses/by-nc-nd/4.0/). 
basales de los pacientes, tipo de procedimiento, mortalidad total, recurrencia de arritmia, mortalidad cardiovascular y necesidad de trasplante. Resultados: Desde enero de 2009 hasta diciembre de 2016 se realizaron 67 procedimientos (38\% de complejos: $19 \%$ de ablación endoepicárdica, $7.5 \%$ de crioablación epicárdica quirúrgica, 3\% de simpatectomía, 3\% de inyección coronaria con alcohol; $6 \%$ de apoyo con oxigenación con membrana extracorpórea) en 41 pacientes (61\% de causa isquémica) por TE. La mortalidad intraprocedimiento fue del 1.5\%. La mediana de seguimiento fue de 23.5 meses (RIQ, 14.2-52.7). Tras el primer ingreso por TE (uno o varios procedimientos), la mortalidad a un año fue de $9.8 \%$. La incidencia acumulada de trasplante cardiaco por TE fue de 2.4\%. En el análisis multivariado, el riesgo de recurrencias arrítmicas o muerte por cualquier causa fue significativamente mayor en pacientes con arritmias clínicas inducibles (HR, 9.03; $p=0.017$ ). Conclusiones: El tratamiento de pacientes con TE, instituido en un centro de referencia y con experiencia, se relacionó con una tasa baja de recurrencia y supervivencia elevada, con una tasa de trasplante cardiaco por TE muy baja. Ante una recurrencia temprana es recomendable practicar un nuevo procedimiento durante el ingreso.

Palabras clave: Tormenta eléctrica. Ablación con catéter. Taquicardia ventricular. Fibrilación ventricular.

\section{Introduction}

Electrical storm (ES) is a medical condition characterized by repeated episodes of ventricular tachycardia (VT) or ventricular fibrillation (VF) that requires three or more interventions in $24 \mathrm{~h}$ for its termination ${ }^{1}$. It is observed in $10 \%$ of patients assessed for implantable cardioverter defibrillator (ICD) shocks ${ }^{2}$ and in up to $4 \%$ of patients with ICD in primary prevention of ischemic conditions ${ }^{3}$. Prognosis is highly adverse in the short and long term, with evidence of an increase in mortality, heart transplantation, and hospitalization, in addition to being accompanied by a high rate of ventricular arrhythmia recurrence $e^{4-6}$. In patients with ES resistant to optimal medical treatment and hemodynamic support, radiofrequency catheter ablation is the treatment of choice ${ }^{7-12}$ and is considered an electrophysiological emergency ${ }^{4,8}$. Clinical practice guidelines recommend early referral of these patients to specialized centers for their care $^{7,9,10}$.

The experience published to date is quite scarce, focused on radiofrequency ablation, and no series has evaluated ES comprehensive interventional treatment ${ }^{11,13}$. The purpose of this study was to assess the prevalence, multimodal invasive treatment results and short- and long-term results of patients with pharmacological treatment-resistant ES in a referral center.

\section{Methods}

\section{Patients}

All patients who underwent at least one ES ablation therapeutic procedure at the authors' center between January 1, 2009, and December 31, 2016, were assessed. All patients were admitted to the Cardiac
Intensive Care Unit, where control of the precipitating factors, continuous monitoring, ICD reprogramming, and advanced hemodynamic treatment procedures were carried out, including counterpulsation balloon or extracorporeal membrane oxygenation (ECMO) support system implementation. Patients received treatment by means of sedation, antiarrhythmic drugs administration, pharmacological sympathetic block, or orotracheal intubation. In the event of lack of response to medical treatment, electrophysiological study or other invasive measures were requested. Only patients who underwent at least one invasive therapeutic procedure aimed at eliminating arrhythmia were included in this study. The study was approved by the center's Ethics Committee for Research.

\section{Interventional cardiology procedures}

All therapeutic procedures carried out in patients for an ES were reviewed. These procedures included radiofrequency catheter ablation electrophysiological studies (endocardial, epicardial, or mixed routes), epicardial cryoablation by surgical approach, sympathectomy, and alcohol injection ablation in a coronary branch or heart transplant. All radiofrequency catheter ablation procedures were carried out using an irrigated tip catheter and $\mathrm{CARTO}^{\circledR}$ or EnSite-NavX ${ }^{\circledR}$ electroanatomical navigation systems; access (endocardial/ epicardial) and ablation modality (clinical VT approach: common technique ${ }^{12}$ or substrate ablation ${ }^{13}$ ) were chosen by the operator according to his/her criteria and patient characteristics. The decision to perform the procedure with ventricular assistance using ECMO was made after considering patient clinical situation and according to the Cardiac Intensive Care Unit team. 
Table 1. Baseline characteristics

\begin{tabular}{|c|c|}
\hline & $n=41$ \\
\hline Male gender $\mathrm{n}(\%)$ & $36(87.8)$ \\
\hline Previous NYHA, n (\%) & $\begin{array}{c}\text { I: } 22(53.6 \%) \\
\text { II: } 15(36.5 \%) \\
\text { III: } 3(7.3 \%) \\
\text { IV: } 0(0 \%) \\
\text { No data:1 }\end{array}$ \\
\hline Age (mean $\pm S D)$ & $61.1 \pm 16.2$ \\
\hline Causes, n (\%) & $\begin{array}{c}\text { Ischemic } 25(61) \\
\text { Non-ischemic } 15(36.6) \\
\text { ACM } 3(7.3) \\
\text { HCM } 1(2.4) \\
\text { DCM } 11 \text { (26.8) } \\
\text { No structural heart disease }\end{array}$ \\
\hline LVEF (median, IQR) & $36(20-45)$ \\
\hline Preserved LVEF ( $\geq 50 \%), n(\%)$ & $3(7.3)$ \\
\hline $\begin{array}{l}\text { Patients with previous VT } \\
\text { ablation procedures, n (\%) }\end{array}$ & $19(46.3)$ \\
\hline
\end{tabular}

NYHA: New York Heart Association functional class; LVEF: left ventricular ejection fraction; IQR: interquartile range; VT: ventricular tachycardia; ACM, arrhythmogenic cardiomyopathy; HCM, hypertrophic cardiomyopathy; DCM: dilated cardiomyopathy.

The patient follow-up was carried out at $1^{\text {st }}, 3^{\text {rd }}$, and $6^{\text {th }}$ months, and then biannually. Medical records were reviewed, and in those individuals coming from other centers, the necessary information was collected through personal contact with the patients or referring physicians.

\section{Study variables}

As the main variable, the combination of ventricular arrhythmia recurrence or death from any cause was considered. As secondary variables, ES recurrence, ventricular arrhythmia (VT/VF) recurrence, death from any cause, cardiovascular death, and the need for transplantation due to ES were analyzed. Long-term efficacy of the procedure was analyzed according to post-ablation VT/VF inducibility test results: absence of inducible arrhythmias (Group A), induction of non-clinical arrhythmias (Group B), induction of clinical arrhythmias (Group C), and failure to perform the post-ablation inducibility test (Group D).

\section{Statistical analysis}

Categorical variables were expressed as numbers and percentages, and continuous variables, as means \pm standard deviations. For comparisons between categorical variables, the Chi-square test or Fisher's test was used. The comparison between quantitative variables was carried out with Student's t-test. Survival and recurrence-free survival analyses and their combinations were performed using Kaplan-Meier's test. The log-rank test was used for survival comparisons. For the multivariate analysis of the risk of adverse episodes, the Cox test was resorted to. Statistical analysis was carried out with SPSS 18.0 and program R, version 3.3.1. $p<0.05$ was considered significant.

\section{Results}

Between January 2009 and December 2016, a total of 67 ES-related therapeutic procedures were carried out in 41 patients at this center (1.63 procedures/patient). Thirty-six cases (87.8\%) corresponded to men, with a mean age of $61.1 \pm 16.2$ years, and 25 individuals $(61 \%)$ had ischemic causes. Mean LVEF was 34.2 $\pm 13 \%$, with three patients $(7.3 \%)$ being observed with LVEF > 50\% and $22(53.6 \%)$ without prior functional class limitation (mean NYHA functional class: $1.49 \pm$ 0.7). Up to 19 subjects (46.3\%) had undergone at least one radiofrequency ablation procedure before the first procedure for ES (Table 1). Patients with medication poisoning, severe electrolyte abnormalities, or unresolved acute ischemia were excluded from the study. Twenty-three patients (56.1\%) underwent coronary angiography within $48 \mathrm{~h}$ before their first therapeutic procedure.

Sixty-seven therapeutic interventions were practiced, out of which $45(62.2 \%)$ were endocardial, $6(9 \%)$ epicardial, 7 (10.4\%) endocardial-epicardial ablation procedures, 5 (7.5\%) were epicardial cryoablation procedures with surgical access, $2(3 \%)$ were sympathectomies, and $2(3 \%)$ were coronary alcohol injection ablations. Table 2 shows short-term efficacy of the different procedures and long-term ES recurrences after these procedures.

On arrival at the electrophysiology laboratory, the presence of spontaneous clinical arrhythmia was identified in $18(43.9 \%)$ procedures (Table 3). There were no significant differences in short-term efficacy of the procedure between patients with spontaneous clinical arrhythmia (14/18 patients, 77.8\%) and those without arrhythmia during ablation (20/23 patients, $87 \%$ ). Common ablation was used in $13(20.6 \%)$, without four sympathectomy and alcohol ablation procedures, and substrate ablation in 50 (79.4\%) being included. In the former case, spontaneous or induced clinical tachycardia mean cycle was of $370.2 \pm 60.3 \mathrm{~ms}$ (median, 360 
Table 2. Types of procedures

\begin{tabular}{|l|c|c|c|}
\hline & Procedures & $\begin{array}{c}\text { Immediate } \\
\text { success* }\end{array}$ & $\begin{array}{c}\text { Chronic } \\
\text { success** }\end{array}$ \\
\hline $\begin{array}{l}\text { Endocardial } \\
\text { ablation }\end{array}$ & 45 & $34(75.5 \%)$ & $22(48.9 \%)$ \\
\hline $\begin{array}{l}\text { Epicardial } \\
\text { ablation }\end{array}$ & 6 & $6(100 \%)$ & $2(33.3 \%)$ \\
\hline $\begin{array}{l}\text { Endocardial- } \\
\text { epicardial } \\
\text { ablation }\end{array}$ & 7 & $6(85.7 \%)$ & $5(71.4 \%)$ \\
\hline $\begin{array}{l}\text { Sympathectomy } \\
\text { Alcohol }\end{array}$ & 2 & $1(50 \%)$ & $1(50 \%)$ \\
\hline $\begin{array}{l}\text { Surgical } \\
\text { cryoablation }\end{array}$ & 5 & $1(50 \%)$ & $1(50 \%)$ \\
\hline Total & 67 & $52(77.6 \%)$ & $33(49.2 \%)$ \\
\hline
\end{tabular}

*Absence of clinical arrhythmia at the end of the procedure.

**Absence of clinical arrhythmia during follow-up.

ms; IQR, 320-410). One patient died in 2014 during the electrophysiological study due to progressive hypotension and resistant shock (1/67, first and only procedure performed on that patient; Table 1, supplementary material). In 2015, implementation of an ECMO program for ES ablation was initiated at this center and four procedures were performed $(4 / 23,17.4 \%$ in those years) with intra-procedural ECMO support, three during endocardial and one for endocardial-epicardial ablation. In these four cases, the ECMO system allowed the procedure to be carried out with adequate hemodynamic stability. Sympathectomies $(n=2)$ were performed by percutaneous puncture and application of anesthetic over the stellate ganglion, with short-term efficacy of $50 \%$. Alcohol ablation procedures $(n=2)$ were carried out in patients with non-ischemic cardiomyopathy, with septal-origin ventricular arrhythmia at the level of the highest portion of the left ventricle (summit) and upper interventricular septum, in patients with previous ineffective attempt at radiofrequency ablation, and with a coronary branch appropriate for occlusion, with short-term efficacy of $50 \%$. Of the 41 patients, 14 (34.1\%) had ventricular arrhythmia recurrence after the first procedure during hospitalization and, after additional treatments, $57 \%$ of them (eight patients) showed no recurrences after the first hospital admission (Fig. 1B).

During the study period (8 years), 1290 months of follow-up were completed in the totality of patients (median: 24 months; IQR, 14.5-52.5). Mean survival time

Table 3. Characteristics of the procedures

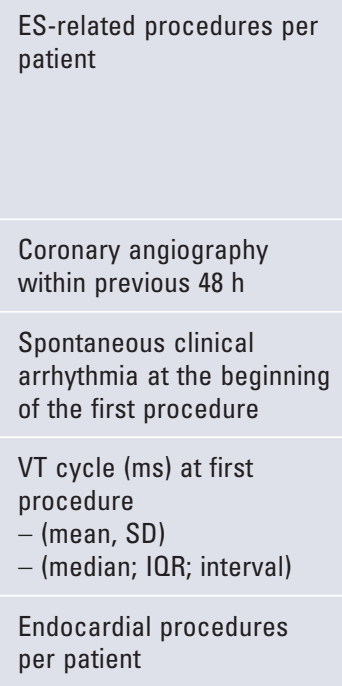

First procedure short-term success

Mortality

Complications

Inducibility at the end of study** $^{*}, \mathrm{n}(\%)$

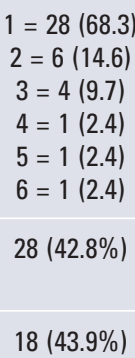

Group A (none): 22 (37.3\%)

Group B (non-clinical): 9 (15.2\%)

Group C (clinical): 6 (10.2\%)

Group D (not evaluated): 22 (37.3\%

Number (\%); mean \pm SD

*Excluded in the percentage of four procedures (two sympathectomies and two alcohol ablations)

**Extrasystole-induced VF is excluded.

after the first hospital admission for ES was $65 \pm 6.1$ months $(95 \% \mathrm{Cl}, 53.1-76.8$; Fig. 1A). After the first admission for ES (one or several procedures), 1-year mortality was $9.8 \%$. Mortality at the end of follow-up was $24.4 \%$ (10/41): six patients (60\%) due to cardiovascular death, four of them during hospitalization: one case of 


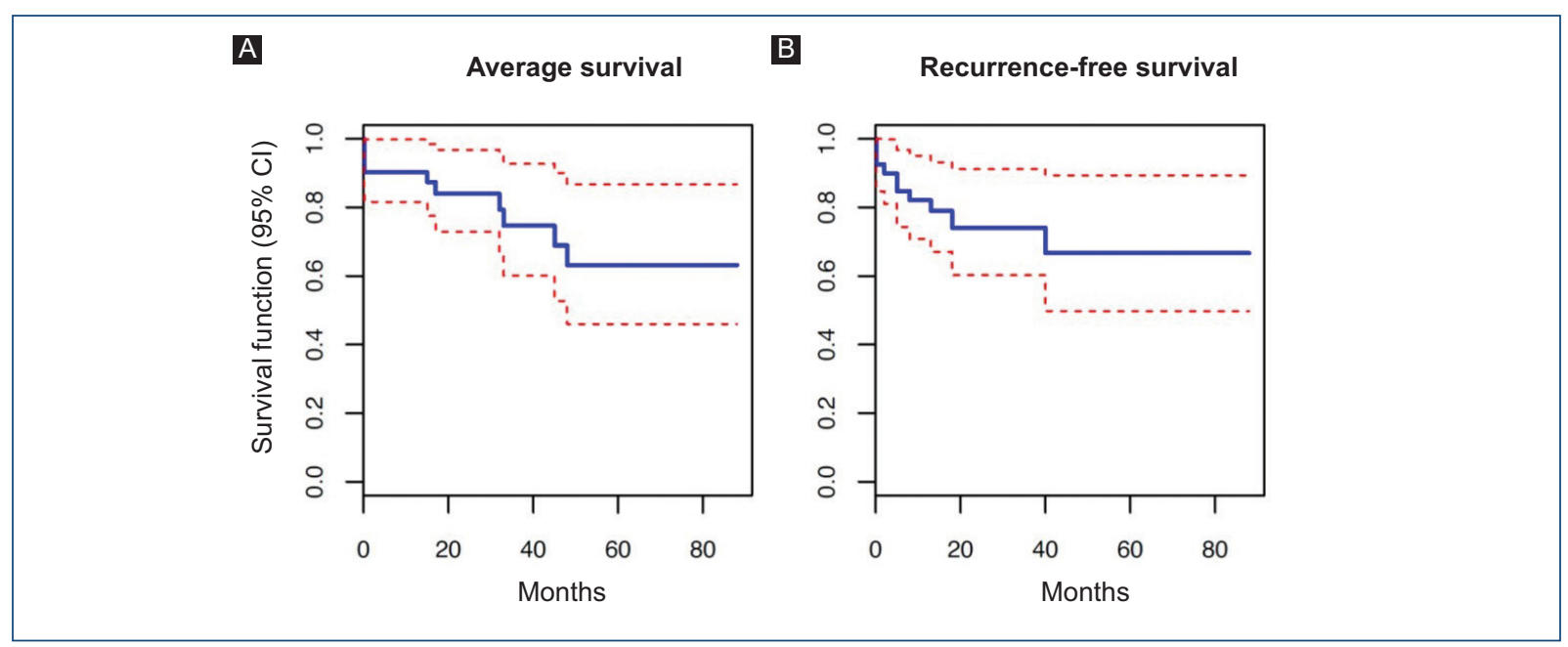

Figura 1. A: survival curve. B: recurrence-free survival after first hospital admission for electrical storm.

cardiogenic shock during the ablation procedure, two ES recurrences during the $1^{\text {st }}$ week after the procedure in patients with failed re-interventions who were not eligible for heart transplantation (due to age and comorbidity), and one patient, who had previously undergone ablation with ECMO support, due to deferred sepsis (Table 1, supplementary material). The cases of late cardiovascular mortality $(n=2)$ were due end-stage heart failure. Four subjects died of non-cardiac causes: one due to septic shock, one to complicated pneumonia, one to distributive shock in a context of ischemic colitis, and one due to non-sudden death of unknown cause. During follow-up, one individual required heart transplantation due to ES recurrence without response to the treatment $(2.4 \%)$. VT/VF inducibility was evaluated at the end of the first intervention in 25 patients (61\%): $2(8 \%)$ had clinical arrhythmias (Group C, no success), 6 (24\%) had non-clinical arrhythmias (Group $\mathrm{B}$, partial success), and 17 (68\%) did not experience inducible arrhythmias (Group A, complete success); in 16 subjects, inducibility was not evaluated at the end of the first procedure for ES, without those with extrasystole-induced VF or poor clinical situation (group D) being included. In the multivariate analysis, only clinical arrhythmia inducibility was a predictor of death or arrhythmia recurrence (HR, 9.034; 95\% $\mathrm{Cl}, 1.49-54.78 ; p=0.017)$, after the first therapeutic procedure for ES (Table 4). No significant differences were observed in the risk of death or VT/VF recurrence according to the functional class before the episode (log-rank $=0.461$ ) or NYHA functional class. After the first admission, patients with an ischemic cause, in comparison with non-ischemic, showed a non-significant trend toward higher all-cause mortality (52 months [ $95 \% \mathrm{Cl}, 36.9-67.2$ vs. 77.5 months; $95 \% \mathrm{Cl}, 64-90.9 ; \mathrm{p}=0.08$; Fig. 1, supplementary material). Multivariate analysis: $\mathrm{HR}=16.34, \mathrm{p}=0.055$, table 4.

Figure 2A shows VT/VF recurrence-free survival at follow-up (Group A [complete success]: $80 \pm 7.3$ months; Group B [partial success]: $54.8 \pm 15.1$ months; Group $C$ [no success]: $4 \pm 3.9$ months; and group $D$ [no test]: $46.6 \pm 9.5$ months). VT/VF recurrence-free survival in Group $C$ was significantly lower than in the other groups together ( $p=0.003)$, and in comparison with Groups A $(p=0.001)$ and $D(p=0.01)$. The rest of intergroup comparisons, including Group C versus Group B $(p=0.15)$, did not reach statistical significance. VT/VF recurrence (Fig. 2B) in patients with inducible arrhythmias (Group C) was significantly higher than in the rest of the groups ( $p<0.05$ for all comparisons) and, in addition, statistically higher in Group D versus Group $A(p=0.01)$. The other intergroup comparisons, including Group A versus Group B ( $p=0.061)$, did not reach statistical significance. All-cause mortality (Fig. 2C) was significantly higher in Group $C$ than in the rest of the groups together $(p=0.017)$, but not in intergroup comparisons ( $C$ vs. $A, p=0.069$; $C$ vs. $B, p=0.118$; and $C$ vs. $D=0.058$ ). The other comparisons showed no statistical significance. There were no differences between groups regarding the time to cardiovascular mortality (Fig. 2D, p > 0.05 for all comparisons).

\section{Discussion}

This study shows that the treatment of patients with ES resistant to usual drug treatment, implemented in a 
Table 4. Predictors of mortality or ES recurrence after the first ablation procedure

\begin{tabular}{|c|c|c|c|c|c|c|c|c|c|}
\hline \multicolumn{10}{|c|}{ a) Univariate analysis } \\
\hline & \multicolumn{3}{|c|}{ Recurrence or death } & \multicolumn{3}{|c|}{ Recurrence } & \multicolumn{3}{|c|}{ Mortality } \\
\hline & $\mathbf{R R}$ & CI $[5 \%, 95 \%]$ & p-value & $\mathbf{R R}$ & CI $[5 \%, 95 \%]$ & p-value & $\mathbf{R R}$ & CI $[5 \%, 95 \%]$ & p-value \\
\hline Male gender & 1.18 & {$[0.26,5.24]$} & 0.826 & 0.643 & {$[0.081,5.095]$} & 0.676 & 0.641 & {$[0.081,5.07]$} & 0.673 \\
\hline Age (per year) & 1.009 & {$[0.976,1.042]$} & 0.601 & 0.989 & {$[0.954,1.026]$} & 0.562 & 1.047 & {$[0.992,1.104]$} & 0.093 \\
\hline $\begin{array}{l}\text { Functional class } \geq \text { III } \\
\text { vs. } \leq \text { II }\end{array}$ & 1.722 & {$[0.379,7.827]$} & 0.482 & 1.26 & {$[0.157,10.12]$} & 0.828 & 1.211 & {$[0.153,9.605]$} & 0.856 \\
\hline $\begin{array}{l}\text { Ischemic versus } \\
\text { non-ischemic cause }\end{array}$ & 0.819 & {$[0.289,2.319]$} & 0.707 & 0.522 & {$[0.146,1.864]$} & 0.316 & 3.611 & {$[0.756,17.258]$} & 0.108 \\
\hline $\operatorname{LVEF}(\%)$ & 1,012 & {$[0.974,1.152]$} & 0.533 & 1,021 & {$[0.974,1.071]$} & 0.386 & 0.977 & {$[0.931,1.026]$} & 0.358 \\
\hline VT cycle (ms) & 1,003 & {$[0.994,1.012]$} & 0.519 & 1,005 & {$[0.994,1.016]$} & 0.38 & 1,003 & {$[0.991,1.015]$} & 0.596 \\
\hline $\begin{array}{l}\text { EPS \# } 1 \text { spontaneous } \\
\text { arrhythmia }\end{array}$ & 0.603 & {$[0.24,1.52]$} & 0.284 & 0.485 & {$[0.125,1.877]$} & 0.297 & 0.585 & {$[0.165,2.077]$} & 0.407 \\
\hline VE that generated VF* & 0.812 & {$[0.182,3.62]$} & 0.785 & 1.175 & {$[0.148,9.315]$} & 0.878 & 0.426 & {$[0.088,2.058]$} & 0.288 \\
\hline $\begin{array}{l}\text { Substrate versus } \\
\text { common abl. }\end{array}$ & 2.752 & {$[0.616,12.298]$} & 0.185 & 1.589 & {$[0.333,7.577]$} & 0.561 & 3.654 & {$[0.459,29.111]$} & 0.221 \\
\hline $\begin{array}{l}\text { Clinical arrhythmia } \\
\text { inducibility }\end{array}$ & 9.034 & {$[1.49,54.783]$} & 0.017 & 14.239 & {$[1.927,102.83]$} & 0.008 & 6.167 & {$[1.107,34.347]$} & 0.038 \\
\hline $\begin{array}{l}\text { Inducibility test } \\
\text { performance }\end{array}$ & 1.117 & {$[0.395,3.156]$} & 0.835 & 1.599 & {$[0.461,5.549]$} & 0.46 & 0.672 & {$[0.173,2.609]$} & 0.566 \\
\hline \multicolumn{10}{|c|}{ b) Multivariate analysis } \\
\hline & \multicolumn{3}{|c|}{ Recurrence or death } & \multicolumn{3}{|c|}{ Recurrence } & \multicolumn{3}{|c|}{ Mortality } \\
\hline & RR & CI $[5 \%, 95 \%]$ & p-value & RR & CI $[5 \%, 95 \%]$ & p-value & $\mathbf{R R}$ & CI $[5 \%, 95 \%]$ & p-value \\
\hline $\begin{array}{l}\text { Ischemic versus } \\
\text { non-ischemic cause }\end{array}$ & & & & & & & 16.34 & [0.94 - 283.22] & 0.055 \\
\hline $\begin{array}{l}\text { Clinical arrhythmia } \\
\text { inducibility }\end{array}$ & 9.03 & [1.49 - 54.78] & 0.017 & 14.24 & [1.19 - 102.83] & 0.008 & 28.24 & {$[2.38-333.45]$} & 0.008 \\
\hline
\end{tabular}

LVEF: left ventricular ejection fraction; EPS \# 1: First Electrophysiological Study for Electrical Storm; VE: ventricular extrasystole; VF: ventricular fibrillation; abl.: ablation.

referral and high-volume center, and based on the use of radiofrequency ablation and different invasive treatments, allows obtaining favorable episode rates during follow-up, in comparison with those recently published ${ }^{10,14}$. This study confirms the need for indicating an invasive and comprehensive treatment, which, in a staggered manner, includes different therapeutic approaches to ES and uses alternative energy sources, endoepicardial, or surgical access, as well as complex antiarrhythmic and specialized techniques, such as sympathetic or alcohol ablation ${ }^{15,16}$. Finally, this study supports the usefulness of ventricular assistance systems for the care of patients with ES and hemodynamic impairment to successfully perform the procedure ${ }^{17}$. All this has allowed improving the figures of survival free of arrhythmic recurrences within a highly specialized treatment, with the participation of different professionals and specialists.

\section{ES interventional treatment prognosis}

ES is an electrophysiological vital emergency, defined by the presence of three or more VT or VF episodes in $24 \mathrm{~h}$; it accounts for 10 to $30 \%$ of VT/VF ablation cases and is related to a significant mortality increase ${ }^{1-6}$. Catheter ablation reduces VT/VF shocks and mortality and prolongs survival ${ }^{18}$.

ES is an extremely complex clinical situation due to the interaction of the effects of electrical instability crisis, multiple defibrillator shocks, and a situation of advanced 


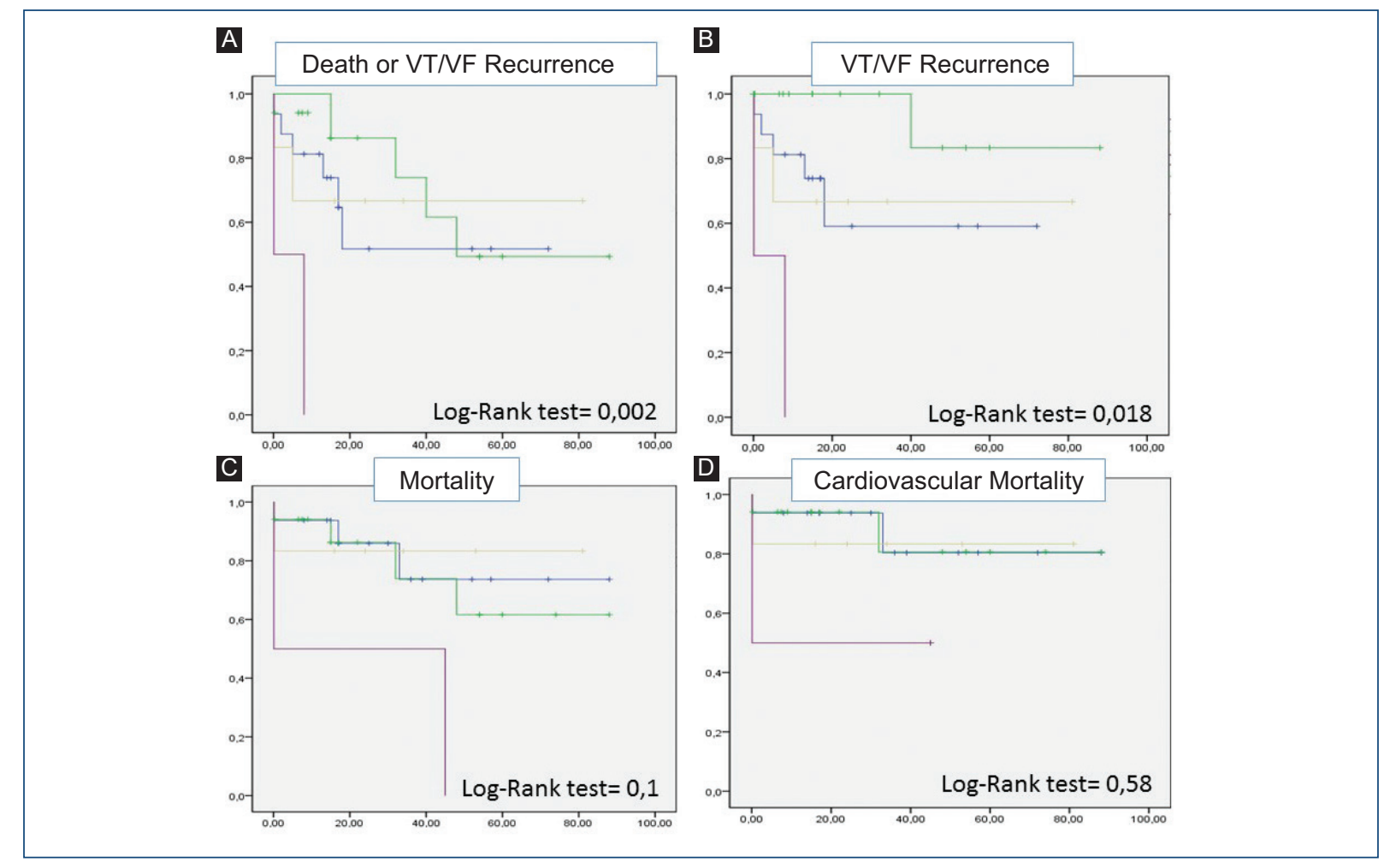

Figura 2. Survival free of recurrence or death from any cause or cardiovascular, in relation to arrhythmia inducibility at the end of the first procedure. Group A (green): absence of inducible arrhythmias; Group B (brown): non-clinical arrhythmia inducibility; Group C (purple): clinical arrhythmia inducibility; and Group D (blue): inducibility not evaluated. Overall inducibility logrank statistical value is shown for each evaluated episode.

heart failure, in which ablation is often not performed or was considered a rescue maneuver as a transition to heart transplantation ${ }^{4,11,19}$. The first published studies showed that ES ablation interrupts arrhythmic instability in a high proportion of cases; however, due to the limited size of the studies and severity of patients' clinical situation, demonstrating a significant improvement in overall survival in comparison with non-invasively-treated ES was not possible ${ }^{14,20}$. However, studies of groups with large volume and the recent VT ablation international multicenter registry show that ES ablation increases long-term survival, almost by $90 \%$ at 1 year in patients with efficacious ablation ${ }^{10,14}$. This study recorded a 1-year survival of $90.2 \%$ and a VT/VF recurrence-free overall survival of $85 \%$ after the first admission. Despite the complexity of the performed procedures $38 \%$ of complex ablations) and ECMO support necessities, early mortality $(9.7 \%)$ and peri-procedural complications incidence $(2.4 \%)$ showed similar figures to those of recent studies $^{5,20}$. On the other hand, there was only one patient with heart transplantation indication due to ES
(1/126 heart transplants, $0.79 \%)$ during the analyzed period. These data suggest that the practice of the intervention in high-volume centers highly significantly reduces the need for urgent heart transplantation in patients with ES. These data are consistent with the recent update of the urgent heart transplantation eligibility criteria established by the National Transplant Organization (ONT - Organización Nacional de Trasplantes) ${ }^{21}$.

\section{Predictors of VT recurrence and long- term mortality}

The persistence of clinical arrhythmias after the therapeutic procedure was shown to be a significant factor of poor prognosis with regard to arrhythmia recurrence and mortality. Patients without inducible clinical arrhythmias did not show a statistically different arrhythmic recurrence rate with regard to those with inducible nonclinical arrhythmias after the procedure. Conversely, in the study by Carbucicchio et al., the absence of inducibility of any ventricular arrhythmia was associated with a lower 
ventricular arrhythmia recurrence rate than the persistence of non-clinical arrhythmia inducibility ${ }^{14}$. However, in the series of the VT international multicenter study, and in line with the results of this study, only the persistence of inducible clinical arrhythmias or the lack of an inducibility test was accompanied by a higher rate of ventricular arrhythmia recurrence ${ }^{10}$. While continued $a b-$ lation until eliminating inducibility of any type of arrhythmia has been shown to be useful, it prolongs the duration of the procedure and increases radiofrequency time and the number of defibrillations, which could compromise short-term patient safety ${ }^{22-24}$. In this same sense, these data suggest that common ablation could produce better recurrence and mortality rates in comparison with substrate ablation. However, in the specific context of an ES ischemic cause, a non-randomized and multicenter study has shown a reduction in VT/VF recurrence $(53 \%$ vs. $81 \%$ ) with an extensive endocardial-epicardial substrate ablation versus regular substrate ablation ${ }^{25}$, with no differences in overall mortality being found. Substrate ablation, which by definition affects a larger amount of tissue, might accentuate functional deterioration in patients who are already in a critical situation with ventricular function severe impairment and clinical compromise. Therefore, in this ES context, there are still doubts about the need to perform too extensive ablations that require complete removal of all the arrhythmic substrate necessary for maintaining any type of ventricular arrhythmia. Finally, no other ablation-related factor, such as spontaneous presence of clinical arrhythmia during the procedure, modified the prognosis regarding the incidence of recurrences or long-term mortality ${ }^{20,26}$.

\section{ES ablation and immediate results}

Radiofrequency ablation with navigation system support was the ablation technique that was initially chosen in all patients. Even though monomorphic VT was the most prevalent clinical situation, variability in VT morphologies and hemodynamic tolerance demanded the use of advanced mapping measures and ablation, as well as hemodynamic support systems. A multidisciplinary team conducted the studies and individualized decisions according to patient baseline situation, preferences, and health-care team professionals' opinion. Ablation was carried out sequentially, and the performance of an endocardial, epicardial, surgical epicardial cryoablation, alcohol ablation, or sympathectomy procedure was decided based on the clinical situation, imaging findings, and initial procedure results ${ }^{15,16,27}$. In $32 \%$, ablation procedures repetition was considered necessary and, in 33\%, non-endocardial therapeutic approaches were resorted to, with good results $(82 \%$ of short-term success), after considering that these were patients with previous failed endocardial ablation procedures. Consequently, these data allow recommending specialized and strict surveillance after the ablation procedure and repeating the ablation procedure, according to all available techniques, in the event of ES recurrence after the first procedure.

The use of ECMO in this series is still limited, but growing. The role of circulatory support in procedures with relapsing arrhythmias improves safety and efficacy of the procedure, which enables efficacious and safe ablation procedures in patients with hemodynamically poorly tolerated arrhythmias ${ }^{17}$. Availability of advanced technology and experience ${ }^{15}$ for multidisciplinary care, especially with regard to these complex interventions, is the key to comprehensive and excellence care for patients with $\mathrm{ES}^{9}$. The authors' initial experience supports the use of hemodynamic support systems in clinically unstable patients, with ES and poor hemodynamic conditions, with a low incidence of short-term complications $(2.4 \%)^{28}$.

This study has some limitations. It is a retrospective protocol, and some clinical variables and procedure results are therefore not available. Antiarrhythmic treatment was left to the discretion of treating physicians and perhaps influenced the clinical course. In addition, by virtue of its design, the study shows the advances of available technology for invasive treatment of arrhythmias and their evolution in time. Ablation was not randomized, but was chosen at the operator's discretion. The results of the multivariate analysis with wide confidence intervals are influenced by the limited sample size. Although it is a case series from a single center, it has the participation of a stable group of professionals, with the same homogeneous therapeutic criteria, which represents a higher robustness of the obtained results.

\section{Conclusion}

The treatment of patients with ES, carried out in a reference center with experience, primarily based on radiofrequency ablation, allows obtaining recurrence and survival rates that are comparable to those published in international reference centers in this clinical situation, with very low ES-related heart transplantation rates. The goal of the procedure should be not to induce clinical arrhythmia and, in case of early recurrence, a new procedure while on hospitalization is recommendable. 


\section{Acknowledgments}

The authors thank the collaboration of María Padilla, from the National Transplant Organization (Spain) and Professor Pedro Saavedra, from the Universidad de Las Palmas de Gran Canaria (Spain), Department of Mathematics.

\section{Funding}

This study received partial funding from "Convocatoria de ayudas a la contratación de investigadores RIC 2014", CIBERCV, Instituto de Investigación Carlos III. Grants Pl13-01882, PI13-00903, Pl14/00857, Pl16/01123, Pl17/01059, TEC2013-46067-R, DTS16/0160 and IJCl2014-22178), and FEDER funds.

\section{Conflicts of interests}

None of the authors has any conflict of interests related to the content of the article.

\section{Ethical disclosures}

Protection of human and animal subjects. The authors declare that the procedures that were followed adhered to the ethical standards of the responsible human experimentation committee and were in agreement with the World Medical Association and the Declaration of Helsinki.

Confidentiality of data. The authors declare that they have followed the protocols of their work center on the publication of patient data.

Right to privacy and informed consent. The authors declare that no patient data appear in this article.

\section{References}

1. Hohnloser SH, Al-Khalidi HR, Pratt CM, Brum JM, Tatla DS, Tchou P et al. Electrical storm in patients with an implantable defibrillator: Incidence, features, and preventive therapy: Insights from a randomized trial. Eur Heart J. 2006;27(24):3027-3032.

2. Verma A, Kilicaslan F, Marrouche NF, Minor S, Khan M, Wazni O, et al. Prevalence, predictors, and mortality significance of the causative arrhythmia in patients with electrical storm. J Cardiovasc Electrophysiol. 2004;15(11):1265-1270.

3. Sesselberg HW, Moss AJ, McNitt S, Zareba W, Daubert JP, Andrews ML, et al. Ventricular arrhythmia storms in postinfarction patients with implantable defibrillators for primary prevention indications: a MADIT-II substudy. Heart Rhythm 2007:4(11):1395-402.

4. Bänsch D, Böcker D, Brunn J, Weber M, Breithardt G, Block M. Clusters of ventricular tachycardias signify impaired survival in patients with idiopathic dilated cardiomyopathy and implantable cardioverter defibrillators. J Am Coll Cardiol. 2000;36(2):566-73.

5. Santangeli P, Frankel DS, Tung R, Vaseghi M, Sauer WH, Tzou WS, et al. Early mortality after catheter ablation of ventricular tachycardia in patients with structural heart disease. J Am Coll Cardiol. 2017;69(17): 2105-2115.

6. Guerra F, Shkoza M, Scappini L, Flori M, Capucci A. Role of electrical storm as a mortality and morbidity risk factor and its clinical predictors: a meta-analysis. Europace 2014;16(3):347-53.
7. Priori SG, Blomström-Lundqvist C, Mazzanti A, Blom N, Borggrefe $M$, Camm J, et al. 2015 ESC Guidelines for the management of patients with ventricular arrhythmias and the prevention of sudden cardiac death: The Task Force for the Management of Patients with Ventricular Arrhythmias and the Prevention of Sudden Cardiac Death of the Europe. Eur Heart J. 2015;36(41):2793-867.

8. Hernández-Hernández JM, Datino T, Arenal Á, Núñez-García A, Fernández-Avilés F. Ventricular fibrillation, an emergency in electrophysiology. Rev Esp Cardiol (Engl. ed) 2012;65(5):482-3.

9. Gorenek B, Blomstrom Lundqvist C, Brugada Terradellas J, Camm AJ, Hindricks G, Huber K, et al. Cardiac arrhythmias in acute coronary syndromes: position paper from the joint EHRA, ACCA, and EAPCI task force. Europace 2014;16(11):1655-1673.

10. Vergara P, Tung R, Vaseghi M, Brombin C, Frankel DS, Di Biase L, et al. Successful ventricular tachycardia ablation in patients with electrical storm reduces recurrences and improves survival. Heart Rhythm 2018;15(1):48-55.

11. Cabrera AMM, Cordero AB, Rodríguez JA, Carmona JR, de Teresa Galván E. Radiofrequency catheter ablation of ventricular tachycardia in patients with an implantable defibrillator. Long-term follow-up. Rev Esp Cardiol. 2005;58(5):491-8.

12. El-Shalakany A, Hadjis T, Papageorgiou P, Monahan K, Epstein L, Josephson ME. Entrainment/mapping criteria for the prediction of termination of ventricular tachycardia by single radiofrequency lesion in patients with coronary artery disease. Circulation 1999;99(17): 2283-9.

13. Ávila P, Arenal A. Substrate ablation of post-infarction ventricular tachycardias. Rev Española Cardiol. (english ed.) 2014;67(7):514-518.

14. Carbucicchio C, Santamaria M, Trevisi N, Maccabelli G, Giraldi F, Fassini G, et al. Catheter ablation for the treatment of electrical storm in patients with implantable cardioverter-defibrillators: short- and long-term outcomes in a prospective single-center study. Circulation 2008;117(4):462-9.

15. Atienza F, Arenal A, Pérez-David E, Elízaga J, Ortuño JE, Ledesma-Carbayo $\mathrm{MJ}$, et al. New diagnostic and therapeutic approaches to treat ventricular tachycardias originating at the summit of the left ventricle: role of merged hemodynamic-mri and alternative ablation sources. Circ Arrhythm Electrophysiol. 2013;6(6):e80-4.

16. García-Morán E, Sandín-Fuentes MG, Álvarez López JC, Duro-Aguado I, Urueña-Martínez N, Hernández-Luis C. Electrical storm secondary to acute myocardial infarction and heart failure treated with left stellate ganglion block. Rev Esp Cardiol (engl. ed) 2013;66(7):595-7.

17. Baratto F, Pappalardo F, Oloriz T, Bisceglia C, Vergara P, Silberbauer J, et al. Extracorporeal membrane oxygenation for hemodynamic support of ventricular tachycardia ablation. Circ Arrhythm Electrophysiol. 2016;9(12):e004492.

18. Tung R, Vaseghi M, Frankel DS, Vergara P, Di Biase L, Nagashima K, et al. Freedom from recurrent ventricular tachycardia after catheter ablation is associated with improved survival in patients with structural heart disease: an International VT Ablation Center Collaborative Group study. Heart Rhythm 2015;12(9):1997-2007.

19. Izquierdo M, Ruiz-Granell R, Ferrero A, Martínez A, Sánchez-Gomez J, Bonanad $\mathrm{C}$, et al. Ablation or conservative management of electrical storm due to monomorphic ventricular tachycardia: differences in outcome. Europace 2012;14(12):1734-9.

20. Peichl $P$, Cihák R, Kozeluhová M, Wichterle D, Vancura V, Kautzner J. Catheter ablation of arrhythmic storm triggered by monomorphic ectopic beats in patients with coronary artery disease. J Interv Card Electrophysiol 2010;27(1):51-9.

21. Organización Nacional de Trasplante. 2017. Available at: http://www.ont. es/infesp/Paginas/Documentaciion.aspx.

22. Yokokawa M, Kim HM, Baser K, Stevenson W, Nagashima K, Della Bella $P$, et al. Predictive value of programmed ventricular stimulation after catheter ablation of post-infarction ventricular tachycardia. J Am Coll Cardiol. 2015;65(18):1954-1959.

23. Fernández-Armenta J, Penela D, Acosta J, Andreu D, Evertz R, Cabrera M, et al. Substrate modification or ventricular tachycardia induction, mapping, and ablation as the first step? A randomized study. Heart Rhythm 2016;13(8):1589-1595.

24. Ruiz Hernandez PM, Loughlin G, Arenal A. Elimination of all inducible ventricular tachycardias as the endpoint for ablation. J Am Coll Cardiol. 2015;66(22):2576.

25. Di Biase L, Santangeli P, Burkhardt DJ, Bai R, Mohanty P, Carbucicchio C, et al. Endo-Epicardial homogenization of the scar versus limited substrate ablation for the treatment of electrical storms in patients with ischemic cardiomyopathy. J Am Coll Cardiol. 2012;60(2):132-141.

26. Nogami A. Mapping and ablating ventricular premature contractions that trigger ventricular fibrillation: trigger elimination and substrate modification. J Cardiovasc Electrophysiol. 2015;26(1):110-115.

27. Acosta J, Fernández-Armenta J, Penela D, Andreu D, Borras R, Vassanelli $F$, et al. Infarct transmurality as a criterion for first-line endo-epicardial substrate guided ventricular tachycardia ablation in ischemic cardiomyopathy. Heart Rhythm 2016;13(1):85-95.

28. García Carreño J, Sousa Casasnovas I, Vicent Alaminos ML, Atienza Fernández F, Martínez Sellés M, Fernández Avilés F. Utilizacion del oxigenador extracorporeo de membrana en pacientes con tormenta electrica: experiencia de un centro terciario. Rev Esp Cardiol. 2019;72(2):182-183. 